\title{
ARECANUT COLLECTING MACHINE BY BELT CONVEYOR MECHANISM
}

\author{
Punithkumar N.K ${ }^{1}$, Nithin P.R ${ }^{2}$, Oswald Titas Rodrigues ${ }^{3}$, Sandeshkumar ${ }^{4}$, Sandeep $\mathbf{S}^{5}$ \\ ${ }^{1}$ Student, Canara Engineering college, Mangalore 574219 \\ ${ }^{2}$ Student, Canara Engineering college, Mangalore 574219 \\ ${ }^{3}$ Student, Canara Engineering college, Mangalore 574219 \\ ${ }^{4}$ Student, Canara Engineering college, Mangalore 574219 \\ ${ }^{5}$ Assistant Professor, Canara Engineering College, Mangalore 574219
}

\begin{abstract}
Agriculture is now one of the most important sectors in the Indian economy. Areca nut Cultivation is one of the major livelihoods of farmers of Kerala and Karnataka. Labour Problems in every sector is leading to mechanization of processes. Agricultural sector is also facing such problem due to which most of the farmers tend to give up the practice. In order to further develop this sector technology has become one of the main components. Typically, dealing with the agriculture sector can entail difficulties relating to a number of factors. Consequently, to overcome such problems, farmers are being encouraged to adopt technology that suits their farm. Research has to be conducted for Areca nut collecting and bagging machine technology to understand more about the current scenario. To overcome the problems of an existing concepts like motorized, engine, solar and pedal operated the proposed design is best suitable for collecting and bagging the areca nut from ground togunny bag. Areca nut cultivation is a long process involving harvesting, moving the areca nut to ground, separating the fruits from bunches, drying, bagging, de-husking, separating. Several machines are being developed to help farmers to aid the aforementioned processes. Areca nut collecting and bagging machine is a new one among them. The machine is intended to collect areca nuts from ground directly to gunny bags fixed in a moveable trolley. After the bag is filled the trolley can also used to move the bags to store rooms. The machine is operated by a person so that farmer alone himself can use it. In addition, it can be used anytime. Another advantage of this machine is that after loading/filling the areca nut from ground to gunny bag and also weight indication is provided to check the weight. Since the machine is manually driven, the machine is ergonomically designed to reduce the user effort. The major enabling mechanism in the machine is rotary gear mechanism that pulls the areca nuts from ground. A belt driven Conveyer carries the collected areca nuts up into the bags.
\end{abstract}

Keywords: Design and fabrication, bagging machine, Indian economy.

\section{INTRODUCTION}

Product design is the process of creating a new product which has to be accepted by the customers. In a broad concept, it is essentially the efficient and effective generation and development of ideas through a process that leads to new product. In a systematic approach, product designers will conceptualize and evaluate ideas, turning them into tangible inventions and products. The product designer's role is to combine art, science, and technology to create new products so, that the consumers can use.

Agriculture is now one of the most important sectors in the Indian economy. The current world productivity of Areca nut is 1.287 tonnes/ha. India is the largest producer of Areca nut in the world. India ranks first in both area (58\%) and production $(53 \%)$ of Areca nut. Areca nut Cultivation is one of the major livelihoods of farmers of Kerala and Karnataka. Research has to be conducted for Areca nut collecting and bagging machine technology to understand more about current scenario. The machine consists of bucket elevator mechanism which are driven by electric motor. The machine is intended to collect areca nuts from ground directly to gunny bags fixed in a movable trolley.

\section{LITERATURE SURVEY}

Jagannath Pattar et al int: The machine is designed which willcollect the areca nut from the floor and fill it to a gunny bag. This machine is operated by a single person in whom little effort is required by the user to operate it.

Farmer: We spoke with farmers and we got feedback about the problem collecting the areca nut from the ground, are now a days farmers facing the labour problem with it.

Industry: Achal industries have made same type of machine for collecting cashew nut. The major problem was while collecting, cashew nut gets away from the collector.

Campco reviews: Campco industry have expressed the difficulty in collecting areca nut manually.

\section{Observations from literature survey}

The collecting machine cannot collect the areca nut when machine movement stops.

The elevator is attached to the wheel therefore the process is slower. 
There is no movement of areca nut towards elevator.

We got feedback from farmer about how we can design the collecting machine for convenience of farmers.

\section{CALCULATIONS}

Speed of the motor: $40 \mathrm{rpm}$

Radius of the drum: $76.2 \mathrm{~mm}$

Height of the bucket: $38.1 \mathrm{~mm}$

Length of the bucket: $500 \mathrm{~mm}$

Distance between two buckects: $250 \mathrm{~mm}$

Length of the conveyor: $3124 \mathrm{~mm}$

Total radius: $76.2 \mathrm{~mm}$

Weight on a bucket: $0.5 \mathrm{~kg}$

Total force on the bucket under the load: $24.53 \mathrm{~N}$

Torque: $1868.8 \mathrm{~N}-\mathrm{mm}$

Require power: 2.828 watts

Collecting rate: $3 \mathrm{~kg}$ per minute

\section{Motor Specifications}

24 volts DC motor

Speed: $40 \mathrm{rpm}$

Max power: $17 \mathrm{~W}$

Max torque: $3.86 \mathrm{~N}-\mathrm{m}$

\section{DESIGN}
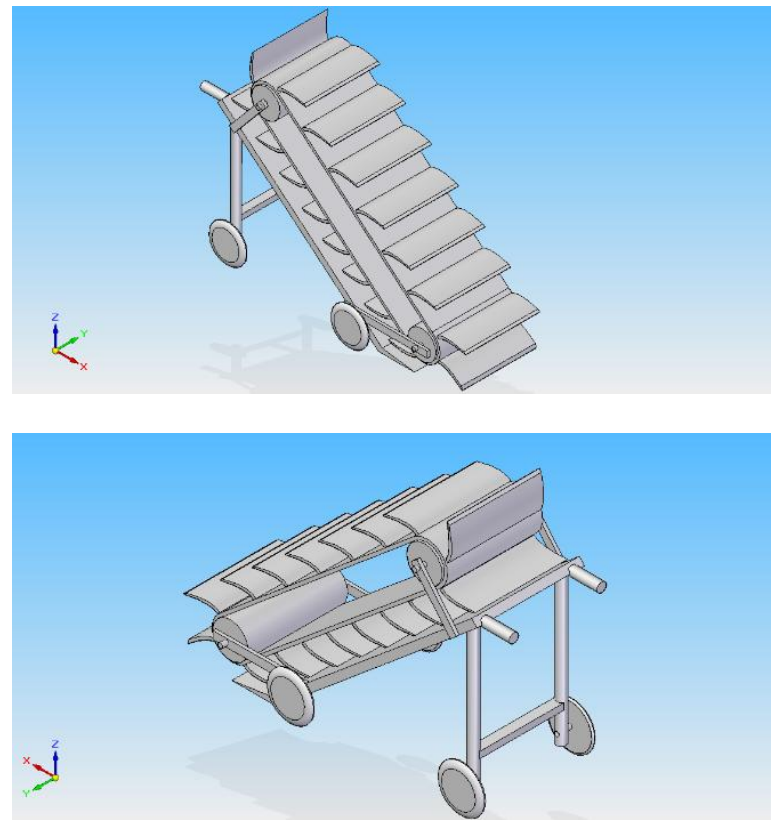

Fig: Design Model of the machine

The model of the machine consists of the following major parts:

$>$ Wiper motor

$>$ Belt conveyor

$>$ Bearings

$>$ Sheet buckets

$>$ Clamps

$>$ Upvc pipes

$>$ Transformer

$>$ Wheels

\subsection{Working Models}
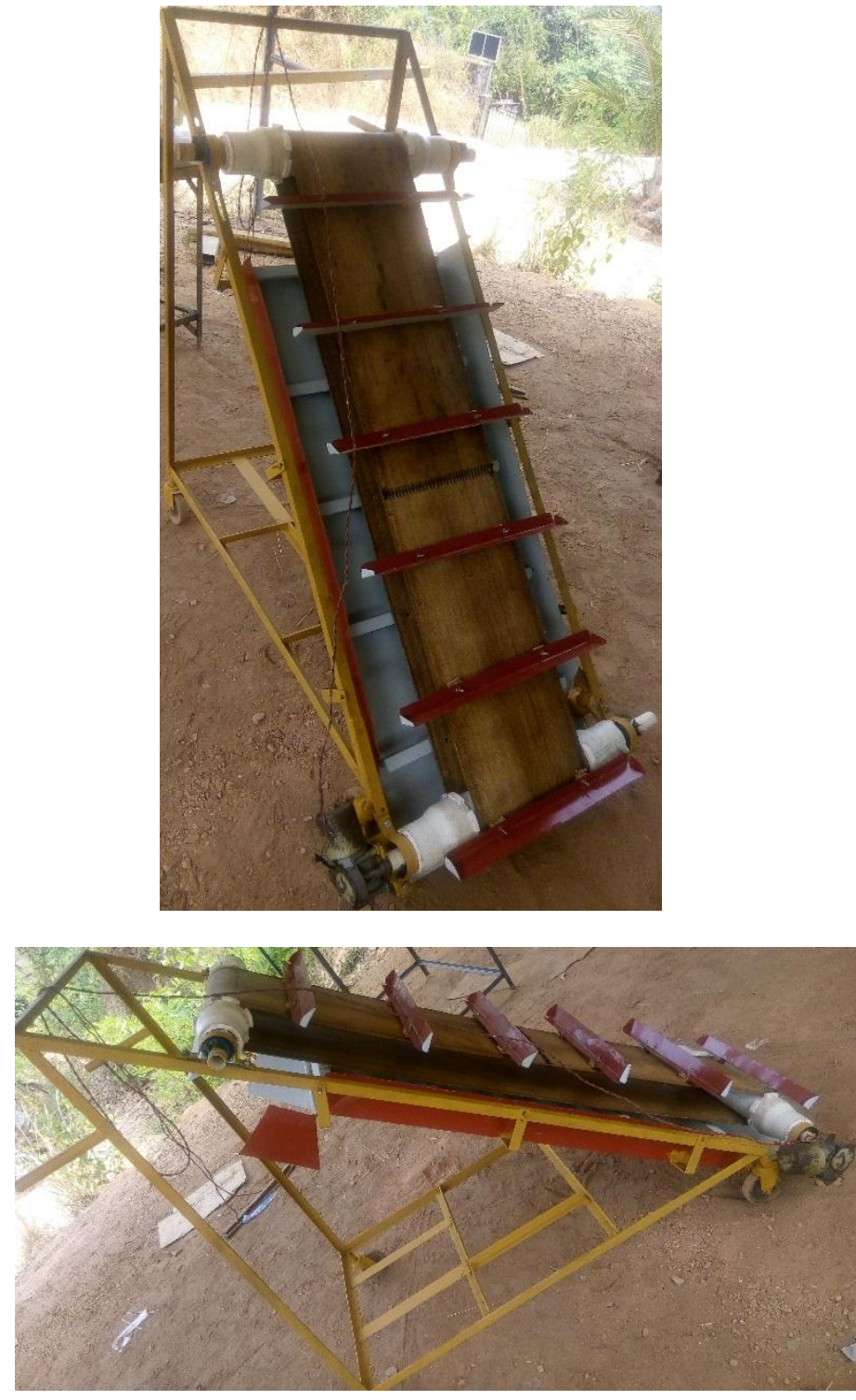

\section{METHODOLOGY}

The whole mechanism used to collect and bag areca nut is mounted on a moveable machine.

The Belt Conveyer is made up of a belt drive consisting of buckets that carry the areca nut in the constrained space.

The rotary gear mechanism consists of rotary drums which is driven by wheels.

The collected areca nuts in buckets is transferred to the collecting bag, at the back of belt elevator.

Product design is the process to full fill the needs of the customer or the market place in which the generated product takes the value. This can be achieved by following below steps which are the stages of Product design. 


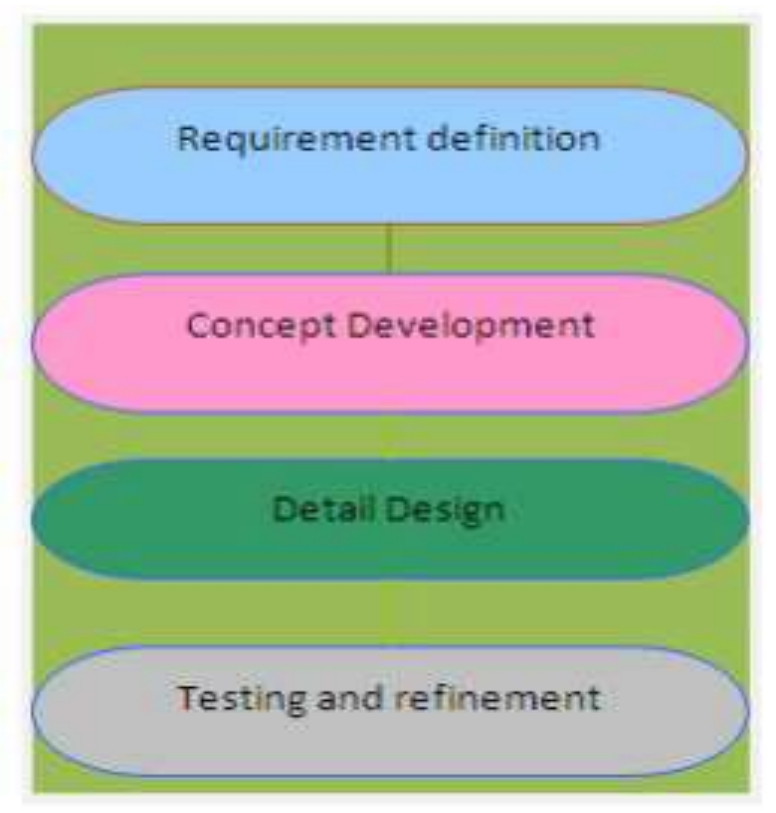

\section{FUTURE SCOPE}

This machine is having many advantages which will help farmers to an extent. Proposed machine will improve the colecting rate of areca nut. It also reduces labour charge and saves time. It also has following advantages over manual collection:

- Cost effective

- Ease of operation

- Single operator is sufficient

- Turning Provision

- Machine can be operated while the operator is standing. So strain to various body parts can be eliminated.

- Single time investment and life time validity.

\section{CONCLUSION}

The collecting machine has a greater potential of increasing the collection rate. Main task is to introduce this new kind of machine to farmers at an affordable price. This machine is made up of simple mechanisms and can be understood by any person. Major task of this machine is to save time and money which is very precious. This will be a smaller contribution towards developing technology in agricultural field.

\section{REFERENCES}

[1] International multidisciplinary research journal (Vol 4 Issue 12 June 2015 ISSN No :2231-5063)

[2] Kiran $\mathrm{K}$ et al Int. Journal of Engineering Research and Applications ISSN : 2248-9622, Vol. 4, Issue 7 ( Version 2), July 2014, pp.109-115

[3] http://www.campco.org/

[4] Machine design text book by Jbk Daas

[5] Design data hand book by balaveera reddy and mahadevan

[6] Internet source

[7] Personal views 